\title{
Twin Pregnancy with One Twin Acardius-Amorphus
}

\author{
Nasreen Noor ${ }^{1}$, Shazia Parveen ${ }^{1}$, Mehkat Ansari ${ }^{2}$, Syed Manazir Ali ${ }^{3}$ \\ ${ }^{1}$ Assistant Professor, ${ }^{2}$ Senior Resident, ${ }^{3}$ Professor, \\ Department of Obstetrics and Gynaecology, Jawaharlal Nehru Medical College, A.M.U., Aligarh, Uttar Pradesh, India.
}

\begin{abstract}
Acephalus Acardia is extremely rare complication of multiple pregnancies and very uncommon congenital malformation disclosed in fetuses and newborns due to twin reverse arterial perfusion syndrome. We report a case of twin pregnancy with one normal fetus and other Acardius Amorphus.
\end{abstract}

Key Words: Acephalus Acardia, Twin reverse arterial perfusion syndrome, Monozygotic twins.

Article History:
Received: 09-06-2016, Revised: 17-06-2016, Accepted: 17-08-2016

\section{INTRODUCTION}

Multiple pregnancy accounts for $1.5 \%$ of all pregnancies, with approximate perinatal morbidity and mortality of $10 \% .{ }^{1}$ Multiple pregnancy is complicated by congenital malformations twice as often as with singletons. Acephalus Acardia is extremely rare complication of multiple pregnancies and very uncommon congenital malformation disclosed in fetuses and newborns due to twin reverse arterial perfusion syndrome. In this condition the donor twin provides circulation for itself and the recipient acardiac twin. The acardiac twin is grossly abnormal with severe reduction anomalies of the upper part of the body. Acardiac "recipient" fetuses may have different morphological forms and often their birth weight is higher than that of the "donor" fetuses. The latter represent morphologic features of circulatory overload due to the necessity of supplying blood to the acardius amorphus fetus. They are usually born preterm with circulatory insufficiency, intrauterine hypoxia and with developmental anomalies. Survival of one of the "donor" fetus implies the necessity of early diagnosis to detect pregnancy pathology, possible intrauterine intervention and monitoring of the healthy twin.

\section{CASE REPORT}

A 25-year-old gravida 1 was referred to us with suspected twin pregnancy at 34 weeks of gestation. Examination revealed a termsized gravid uterus with multiple fetal parts and an increased amount of amniotic fluid. Fetal heart sounds could not be localized. Investigations included complete blood count, urinalysis, syphilis screening, and blood glucose measurement. Ultrasonography revealed a monozygotic twin pregnancy with 1 acardiac fetus and 1 normal fetus with polyhydramnios (amniotic fluid index -24). The acardiac twin had absent upper limbs with absent head while the other twin had no visible malformation or features of congestive cardiac failure. Estimated fetal weight was

\section{${ }^{*}$ Correspondence to:}

\section{Dr. Nasreen Noor}

L-Block 107,

Safina Apartment,

Medical Road, Aligarh, U.P, India.

\begin{tabular}{|l|c|}
\hline \multicolumn{2}{|c|}{ Access this article online } \\
\hline $\begin{array}{l}\text { Website: } \\
\text { www.ijmrp.com }\end{array}$ & Quick Response code \\
\hline DOI: & \\
10.21276/jmrp.2016.2.5.044 & \\
\hline
\end{tabular}

$2.5 \mathrm{Kg}$ for the pump twin and $2.7 \mathrm{Kg}$ for the recipient twin. The mother was plan for caesarean section in view of both breech presentation , followed by delivery of 2 male fetuses weighing 2.4 and $2.6 \mathrm{~kg}$ (twin $A$ and twin $B$, respectively), with a normal single placenta. Twin B was acardius-amorphous (Figure 1), the head and neck were absent, and the trunk and upper extremities were not developed. The other twin was normal and had no features of hydrops (Figure 2). There was no obvious placental anomaly. The post-operative period was uneventful and the patient was discharged on $6^{\text {th }}$ postoperative day.

\section{DISCUSSION}

Acardiac twinning is a rare congenital anomaly characterized by formation of a malformed fetus with an absent or rudimentary (but nonfunctional) heart. A variety of acardiac twins have been described based on the degree of cephalic and truncal maldevelopment. The acardiac-acephalus fetus has no cephalic development, while an acardius-anceps fetus has some cranial structures and/or neural tissue development. The acardiusacormus fetus has cephalic structures with limited or no truncal development. The fourth type, the acardius-amorphus fetus, has the most severe malformation and lacks all cephalic and truncal differentiation. $^{2}$

Acardiac anomaly usually occurs in monozygotic twins, although there are a few reports of dizygotic twins with a fused placenta. It is more common in female twins, and because the disorder is monozygotic, the twins are usually of same gender. The etiopathogenesis of this anomaly is abnormal placental vascular communication between the twins, leading to imbalance of interfetal circulation. Reversed blood flow in the umbilical artery of the acardiac twin causes atrophy of the heart and other organs. ${ }^{3}$ This flow pattern has been termed "twin reversed-arterial- 
perfusion" (TRAP) sequence, in which the lower body of the fetus receives blood with more oxygen saturation and nutrients than the upper body, leading to maldevelopment of the head, neck, and upper extremities. The twin with cardiac activity may be hydropic or malformed in $9 \%$ of cases. This twin is often at high risk for congestive cardiac failure due to increased cardiovascular demand, resulting in preterm delivery. Perinatal mortality for the pump twin has been estimated to be up to $55 \%$, while it is usually fatal for the acardiac twin. ${ }^{4}$

Termination of pregnancy should be considered if acardiac twinning is diagnosed early in the pregnancy. However, early recognition and active management of the TRAP syndrome with maternal digoxin and indomethacin therapy can salvage the pump twin. This protocol has been reported to prevent congestive cardiac failure in the pump twin and polyhydramnios in the mother. Following are the strategies for managing the TRAP syndrome based on the published literature.

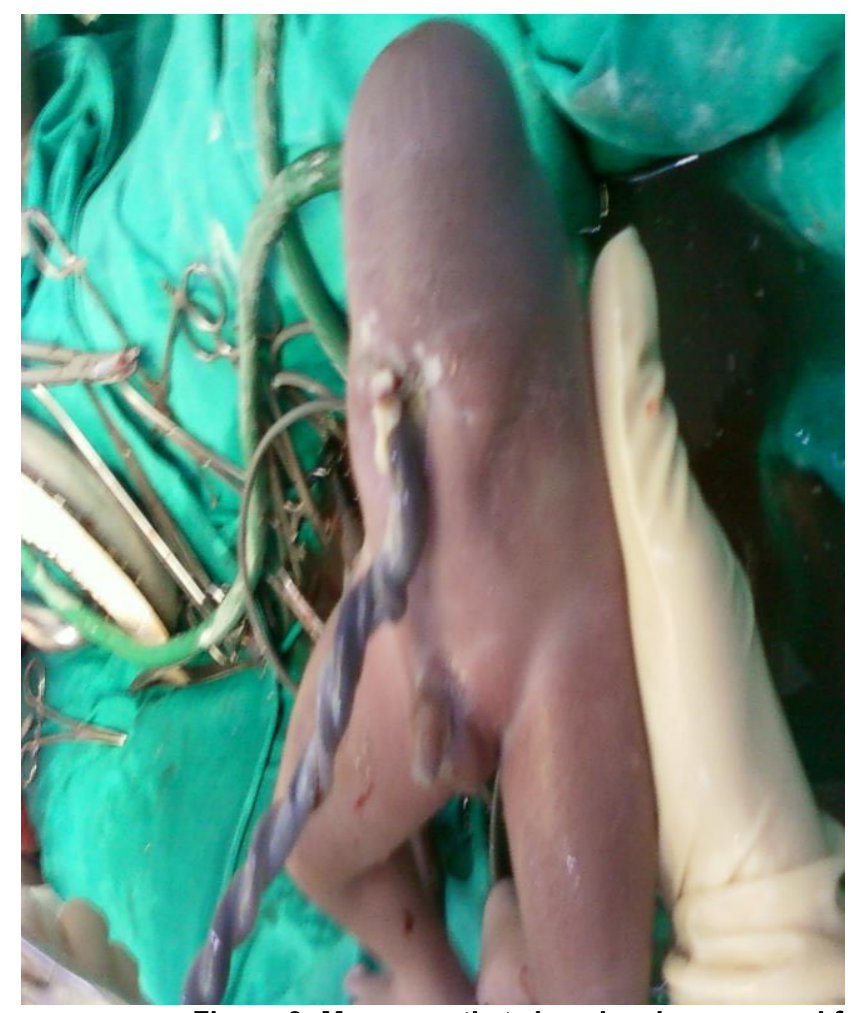

Figure 2: Monozygotic twins showing a normal fetus (right) and an acardius-amorphus fetus (left).

After exclusion of chromosomal aberrations and malformations of the pump twin, close sonographic follow-up may be initiated.

Cord occlusion has been attempted by embolization, cord ligation, laser coagulation, bipolar diathermy, and monopolar diathermy, while intrafetal ablation has been performed with alcohol, monopolar diathermy, interstitial laser, and radiofrequency. ${ }^{5}$ With radiofrequency ablation, greater than $90 \%$ survival can be achieved in monochorionic diamniotic pregnancies complicated by TRAP sequence. ${ }^{6}$ An exact preoperative evaluation of the vascular flow including Doppler sonography is, however, mandatory. By virtually disconnecting the twins, transfusion of blood between them can be stopped. In a recent analysis, intrafetal ablation was associated with a longer duration of treatment delivery interval, greater gestational age at delivery, lower technical failure rate, lower rate of preterm deliveries, reduced rupture of membranes before 32 weeks, and a higher

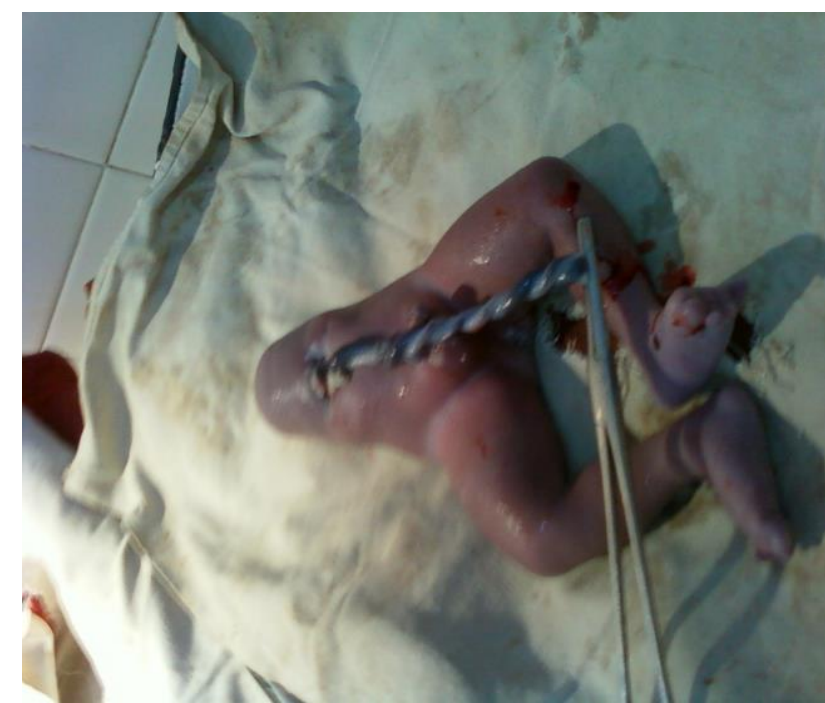

Figure 1: An Acardius-Amorphus fetus

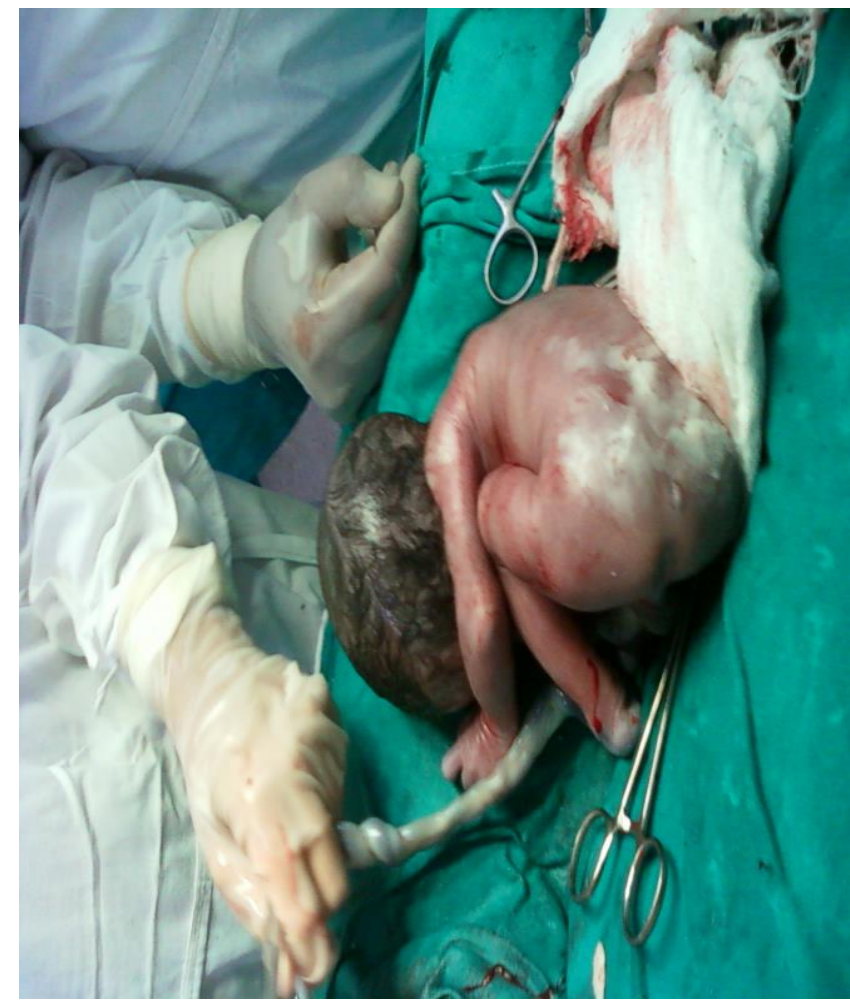

rate of clinical success than cord occlusion techniques.

\section{CONCLUSION}

Termination of pregnancy should be considered if acardiac twinning is diagnosed early in the pregnancy. Conservative treatment is best suited for salvation of the pump twin when the acardiac twin is less than one fourth the weight of the pump twin and there are no signs of impending heart failure. ${ }^{7}$ Invasive intervention is justified when the acardiac twin exceeds $70 \%$ of that of the pump twin; however, the prognosis appears to be poor. Intrafetal ablation is the treatment of choice because it is simpler, safer, and more effective than cord occlusion techniques.

\section{ACKNOWLEDGEMENT}

Thanks to the department of OBGY and Department of Paediatrics for their cooperation and support. 
Nasreen Noor et al. Twin pregnancy with one twin acardius-amorphus

\section{REFERENCES}

1. Hrubec $Z$, Robinette $C D$. The study of human twins in medical research. N Engl J Med 1984;310:435-441. [PubMed]

2. Chen CP, Shih SL, Liu FF, et al. Skeletal deformities of acardius anceps: The gross and imaging features. Pediatr Radiol 1997. 27:221-225. [PubMed]

3. Hanafy A, Peterson CM. Twin-reversed arterial perfusion (TRAP) sequence: case reports and review of literature. Aust N Z J Obstet Gynaecol 1997. 37:187-191. [PubMed] .

4. Moore TR, Gale S, Benirschke K. Perinatal outcome of fortynine pregnancies complicated by acardiac twinning. Am J Obstet Gynecol 1990. 163:907-912. [PubMed]

5. Tan TYT, Sepulveda W. Acardiac twin. A systematic review of minimally invasive treatment modalities Ultrasound Obstet Gynecol 2003. 22:409-419. [PubMed]

6. Lee $H$, Wagner AJ, Sy E, Ball R, et al. Efficacy of radiofrequency ablation for twin-reversed arterial perfusion sequence. Am J Obstet Gynecol 2007. 196:459. e1-4. [PubMed]
7. Weisz B, Peltz R, Chayen B, et al. Tailored management of twin reversed arterial perfusion (TRAP) sequence. Ultrasound Obstet Gynecol 2004. 23:451-455. [PubMed]

\section{Source of Support: Nil. Conflict of Interest: None Declared.}

Copyright: (c) the author(s) and publisher. IJMRP is an official publication of $\mathrm{lbn}$ Sina Academy of Medieval Medicine \& Sciences, registered in 2001 under Indian Trusts Act, 1882.

This is an open access article distributed under the terms of the Creative Commons Attribution Non-commercial License, which permits unrestricted non-commercial use, distribution, and reproduction in any medium, provided the original work is properly cited.

Cite this article as: Nasreen Noor, Shazia Parveen, Mehkat Ansari, Syed Manazir Ali. Twin Pregnancy with One Twin Acardius-Amorphus. Int J Med Res Prof. 2016; 2(5):206-08. 